\title{
AVALIAÇÃO DO SISTEMA DE DRENAGEM URBANA DA BACIA DO PARACURI: A NECESSIDADE DA INTEGRAÇÃO ADEQUADA DOS SISTEMAS DE SANEAMENTO PARA A EFICIÊNCIA DA DRENAGEM URBANA NOS BAIRROS PONTA GROSSA E PARACURI, EM BELÉM/PA.
}

Joniel Belo Saraiva - jonielsaraiva@gmail.com

Universidade Federal do Pará (UFPA)

Allan Bruce Paiva de Morais - brucedmorais@gmail.com

Universidade Federal do Pará (UFPA)

Karla Karoline Leite do Rosário - karlaleite93@ gmail.com Universidade do Estado do Pará (UEPA)

Laércio dos Santos Rosa Junior - laerciojr_14@ hotmail.com

Universidade Federal do Pará (UFPA) 


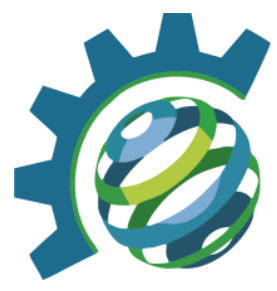

\section{RESUMO}

O aumento da população, sobretudo nas regiões em crescimento e a expansão irregular da periferia, tem ocasionado impactos significativos na infraestrutura dos recursos hídricos e nos sistemas de saneamento. Dentre os impactos que ocorrem, quanto à drenagem urbana, pode-se destacar: o aumento da frequência e a magnitude das inundações; diminuição da qualidade de vida; degradação ambiental e comprometimento dos dispositivos de drenagem, em virtude das deficiências nos sistemas de coleta esgoto e de gerenciamento dos resíduos sólidos. Nesse contexto, o presente trabalho tem como objetivo avaliar as condições dos sistemas de micro a macrodrenagem e as consequências que a deterioração, tal como a falta de manutenção desses sistemas, aliada à falta de planejamento urbano, podem provocar na saúde e bem estar da população que reside na Bacia do Paracuri, além do comprometimento do meio ambiente como um todo. A metodologia do estudo compreende o levantamento bibliográfico teórico (acerca dos conceitos e fundamentos da drenagem urbana) e documental (acerca das informações sobre os sistemas existentes), somado à coleta de dados em campo por meio de registros fotográficos e anotações sobre as condições da drenagem urbana nos bairros Ponta Grossa e Paracuri, em Belém do Pará. Com base nos resultados, pôde-se concluir sobre as mudanças que deveriam ocorrer no sistema de drenagem urbana da área em estudo; sobre as interferências do mau uso e ocupação do solo, da deficiência na coleta de esgoto e da disposição inadequada dos resíduos sólidos. Também foi possível sugerir a adoção de tecnologias de melhoramento do sistema de drenagem existente.

Palavras-chave: Drenagem Urbana, Bacia do Paracuri, Ponta Grossa.

\section{INTRODUÇÃO/OBJETIVO}

O Brasil, a partir da segunda metade do século XX, passou por um acelerado processo de urbanização, influenciado principalmente pela industrialização das cidades brasileiras, que foram transformadas nos principais centros de oferta de emprego devido as poucas oportunidades trabalhistas no meio rural (SANTOS, 2009). Concomitante a esse fenômeno, o êxodo rural intensificou-se rapidamente. Segundo o Instituto Brasileiro de Geografia e Estatística (IBGE), no Censo Demográfico de 2010, entre os anos de 1960 e o ano de estudo em questão, a população urbana cresceu de $45,1 \%$ para $84,4 \%$, enquanto o a população rural diminuiu de $54,9 \%$ para $15,6 \%$.

Como consequência desse processo, as cidades cresceram rapidamente e de forma desordenada, trazendo diversas alterações para o meio urbano, como a criação de zonas em que a população encontra-se desprovida de infraestruturas básicas e de serviços públicos, ocasionando uma má qualidade de vida e aumentando a desigualdade social.

Além disso, a urbanização desordenada provocou diversas alterações na rede hidrográfica e no meio ambiente urbano, como: a canalização e retificação de rios e igarapés; a constante impermeabilização do solo, tendo, por conseguinte a diminuição nas taxas de infiltração e o aumento no volume escoado superficialmente; a contaminação dos corpos d'água, devido à falta de sistemas abrangentes de coleta e tratamento de esgoto; e a expansão de habitações precárias, construídas em encostas de morros e de rios, produzindo erosão e assoreamento (TREVISOL \& BACK, 2011). 


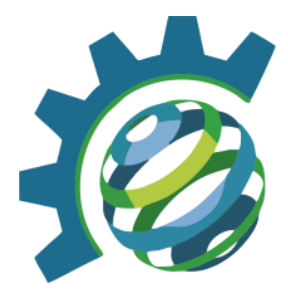

Nesse contexto, o desenvolvimento urbano brasileiro tem produzido um aumento caótico na frequência dos alagamentos, o qual traz prejuízos de ordem material para a população afetada, como a perda de móveis e objetos, além de influenciar em transtornos no trânsito e aumentar a contaminação por doenças de veiculação hídrica.

$\mathrm{Na}$ cidade de Belém, o sistema de drenagem não acompanhou o desenvolvimento urbano, tornando-se ineficiente e obsoleto, devido sua incapacidade em escoar adequadamente as águas pluviais, provocando constantes alagamentos que se intensificam devido ao alto índice pluviométrico registrado durante o inverno amazônico, às marés altas e à grande quantidade de resíduos dispostos inadequadamente nos sistemas de micro e macrodrenagem. Esses problemas não se restringem às áreas periféricas, porém, são essas regiões que sofrem ainda mais com os problemas das cheias urbanas, justamente por serem espaços menos saneados e não disporem de estruturas de micro e macrodrenagem condizentes com as necessidades locais (FRAGOSO et al, 2016).

Em Belém, a bacia do Paracuri, localizada na zona de expansão do município, ilustra muito bem essa realidade. Seu processo de ocupação do espaço urbano, segundo Rodrigues $e t$ al (2016), se deu, em grande medida, de forma espontânea, com precariedade de infraestrutura urbana e com a construção de habitações nas porções mais baixas do território e próximo aos cursos d'água.

Dessa forma, o presente trabalho tem como objetivo avaliar as condições dos sistemas de micro a macrodrenagem e as consequências que a deterioração, tal como a falta de manutenção desses sistemas, aliada à falta de planejamento urbano, podem provocar na saúde e bem estar da população que reside na Bacia do Paracuri, além do comprometimento do meio ambiente como um todo.

\section{METODOLOGIA}

O estudo foi desenvolvido no período compreendido entre o início do mês de janeiro e o final do mês de fevereiro, em 2017. A metodologia do estudo compreendeu as seguintes etapas, em ordem cronológica:

I. Levantamento bibliográfico teórico (acerca dos conceitos e fundamentos da drenagem urbana) em artigos, livros e sites relacionados;

II. Levantamento de dados documentais (acerca das informações sobre o sistema existentes);

III. Coleta de dados em campo por meio de registros fotográficos e anotações sobre as condições da drenagem urbana nos bairros Ponta Grossa e Paracuri, em Belém do Pará.

\section{RESULTADOS E DISCUSSÃO}

\subsection{Caracterização da Área de Estudo}

A área em estudo está inserida na bacia do Paracuri, localizada na porção noroeste da Região Metropolitana de Belém (BANDEIRA, 2004), com 14,60 km² de extensão territorial, sendo $1,02 \mathrm{~km}^{2}(6,99 \%)$ de área alagável e 13,58 km² $(93,01 \%)$ de não alagável (GOMES, 2014). Pertence ao Distrito Administrativo de Icoaraci (DAICO), abrangendo em sua totalidade os bairros do Paracuri, Agulha e o Parque Guajará, e de maneira parcial, os bairros 


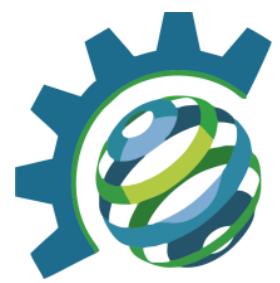

do Tapanã, Parque Verde e Ponta Grossa (Figura 1). Possui uma população estimada de 230.000 habitantes, com densidade populacional de 73, 88 hab/ha, com um total de 62.221 habitantes morando em assentamentos precários (RODRIGUES, 2016).

Figura 1 - Bacia hidrográfica do Paracuri

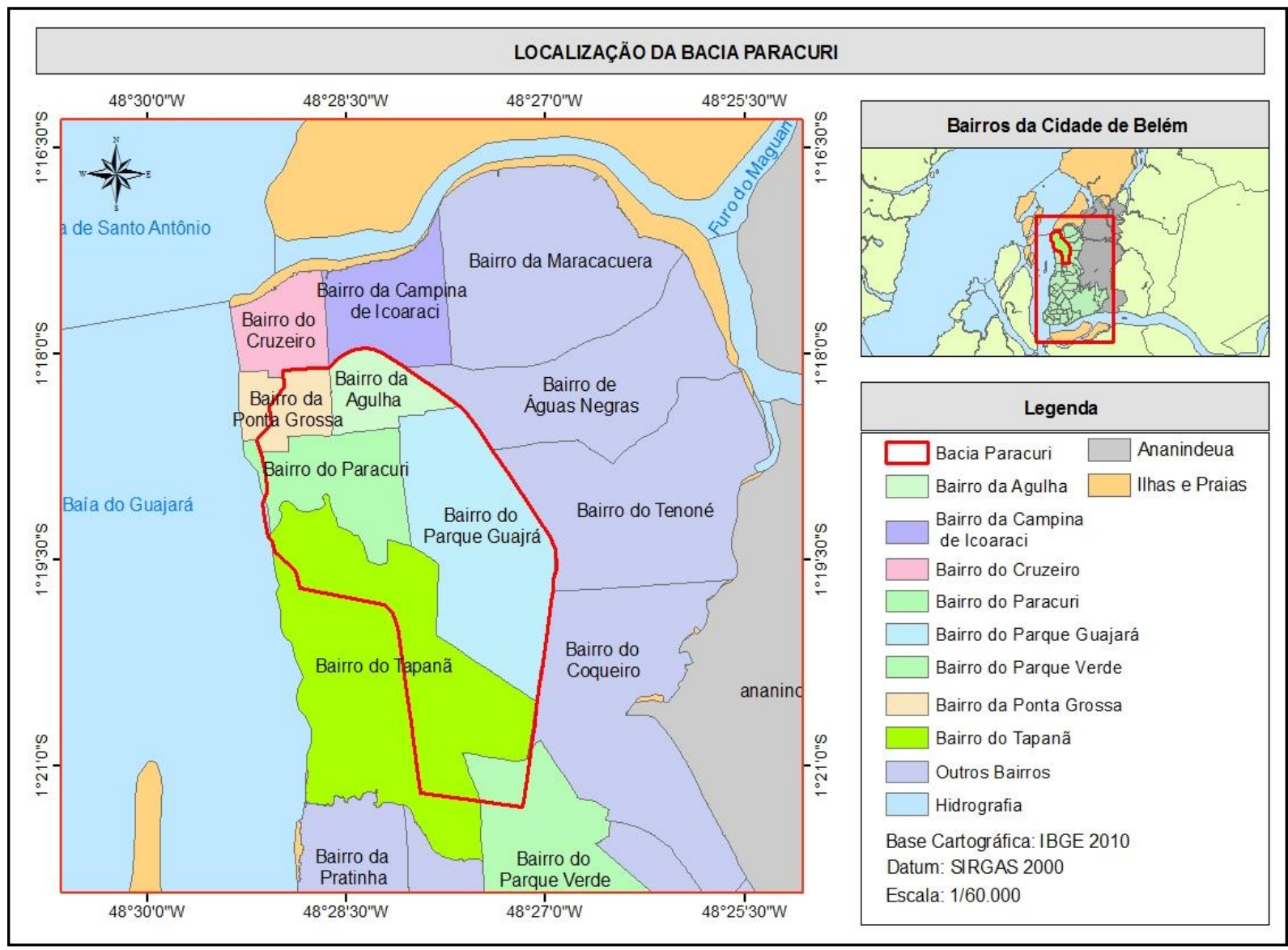

O bairro é cortado pelos Igarapés Paracuri e Livramento, de margens naturais, que perfazem um total de $13.860 \mathrm{~m}$ de extensão (MATTA, 2004), sendo considerados um dos principais meios de transporte, fonte de alimento e renda para a população residente no Paracuri e no Distrito Icoaraci. Além disso, destaca-se como características da bacia, a grande superfície permeável; a baixa densidade populacional; a navegabilidade dos cursos d'água, que dispõem, em sua maior parte, de leito natural e área vegetada no entorno; e o uso do solo predominantemente habitacional (RODRIGUES, 2016). Para ter acesso ao Distrito de Icoaraci, tem-se como principais vias de acesso as Rodovias Augusto Montenegro, Artur Bernardes, Tapanã e Maracacuera.

O diagnóstico dos sistemas de micro e macrodrenagem foi realizados nos bairros do Paracuri e Ponta Grossa, periferia do distrito de Icoaraci. É perceptível a ocupação desordenada da população, onde a maioria são famílias de baixa renda que ocupam as áreas de várzea, tudo isso é reflexo da falta de políticas públicas voltadas ao planejamento urbano, como também a ineficácia do plano diretor da cidade de Belém. 

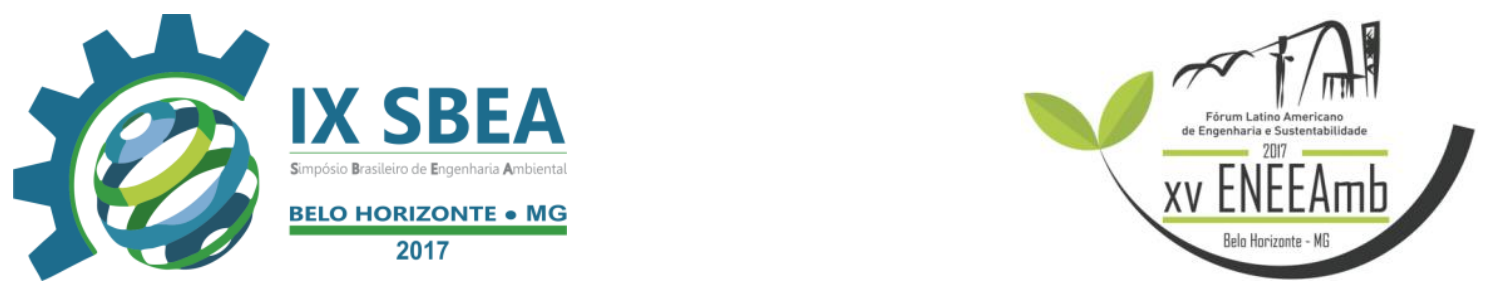

\subsection{Diagnóstico do Sistema de Drenagem Existente}

Os impactos sobre a drenagem urbana na bacia hidrográfica do Paracuri foram registrados, principalmente, nos bairros Paracuri e Ponta Grossa, que possuem áreas de menor cota topográfica (abaixo de $4 \mathrm{~m}$ ), constituindo regiões periféricas do distrito de Icoaraci. São áreas que constantemente sofrem com os alagamentos no primeiro trimestre do ano, período que registra os maiores índices pluviométricos, devido as deficiências do sistema de drenagem.

Foram observados diversos pontos em que não há a existência de sarjetas, enquanto em outros, estas estão deterioradas. Esse deterioramento se dá pela constante obstrução deste dispositivo da microdrenagem, por conta de sedimentos (areias depositadas por moradores, irregularmente) nas vias públicas e acabam sendo carreados pela chuva, depositando-se nas sarjetas e reduzindo sua capacidade de escoamento.

Além disso, é comum encontrarmos resíduos dispostos irregularmente em local público, como esquinas de ruas (Figura 2), constituindo um agravante para o mau funcionamento dos dispositivos da drenagem urbana. $\mathrm{O}$ acumulo de resíduos, sem acondicionado adequado, além de se configurar como criadouro para vetores de doenças, também pode estar sujeito ao entupimento de sarjetas e bocas de lobo, bem como ao assoreamento de canais, que como consequência intensifica os alagamentos.

Figura 2 - Disposição irregular de resíduos sólidos

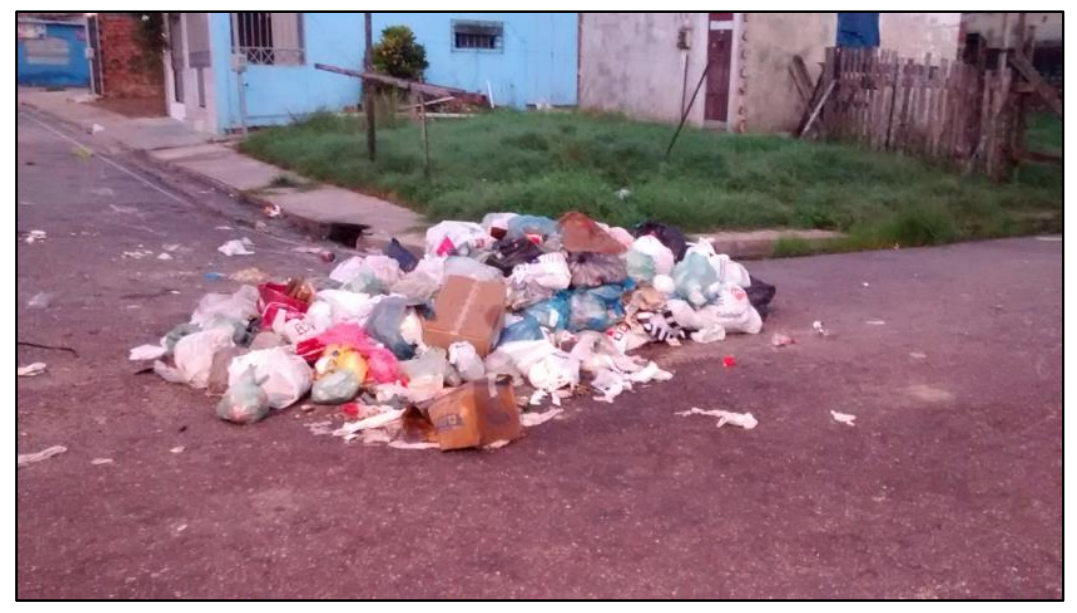

Concomitante ao mau funcionamento dos dispositivos de drenagem urbana, pôde-se observar que os problemas referentes ao esgotamento sanitários na área em estudo são evidentes, pois percebe-se a cor cinza do efluentes lançados nas sarjetas. Os bairros Paracuri e Ponta Grossa, em sua grande maioria, não possuem redes coletoras de esgoto, fator que também acentua os impactos dos alagamentos, pois devido à ausência desses sistemas, a população faz o lançamento do esgoto doméstico diretamente na rede de drenagem urbana, diminuindo a capacidade das sarjetas, bocas de lobo e galerias, em virtude do aumento de vazão depositado nestes dispositivos, que acaba ultrapassando a vazão de projeto do sistema de drenagem. $\mathrm{O}$ esgoto despejado no sistema de drenagem possui muitos nutrientes que após algum tempo criam um ambiente propicio ao desenvolvimento de vegetação, que obstrui as sarjetas e a entrada das bocas e lobo (Figura 3). 


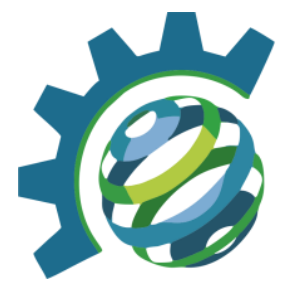

Figura 3 - Boca de lobo obstruída

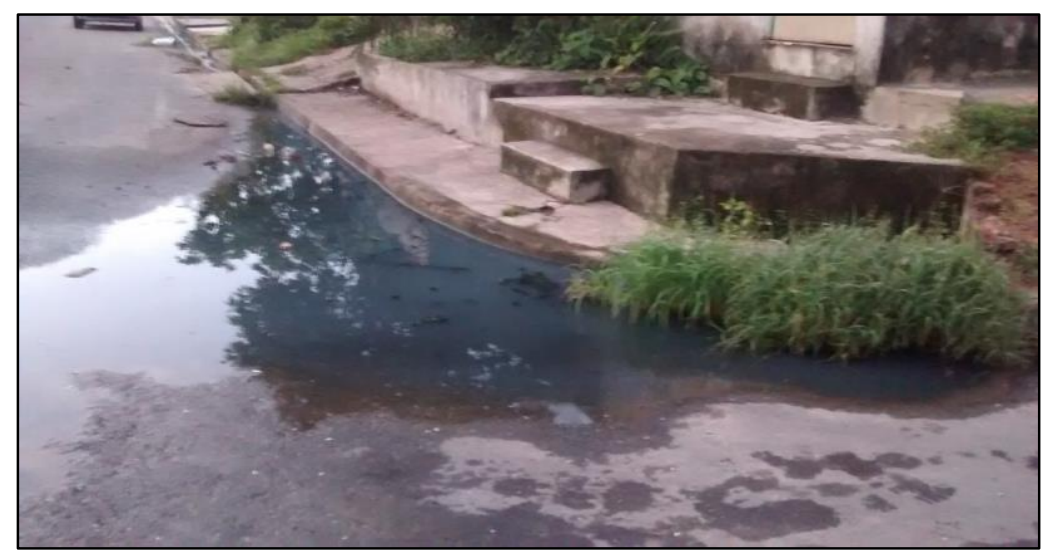

Outro problema observado é a instalação de bocas de lobo em locais incorretos, como nas curvas das vias. Além disso, a falta de manutenção e erros de projetos, também são fatores que acentuam os impactos causados pela drenagem urbana.

No que diz respeito a macrodrenagem, os igarapés Paracuri e Livramento estão constantemente associados aos maiores problemas da região, pois sempre nos períodos de chuvas intensas, os rios ocupam as áreas de várzea, causando inundações nas residências da população que habita o leito maior dos rios, provocando a perda de móveis e objetos. Muitos moradores elevaram suas residências com o intuito de evitar a entrada da água nos períodos de cheia.

O igarapé Paracuri, constituído de leito natural sofreu um estrangulamento próximo à Travessa Berredos, fazendo com que sua vazão diminuísse e ocorresse o acúmulo de sedimentos, inclusive de matéria orgânica. A largura que antes era de aproximadamente 5 $\mathrm{m}$, passou a ser de $1 \mathrm{~m}$, evidenciando uma mudança brusca de escoamento e criando um tipo de lagoa (Figura 4). O estreitamento do canal ocorreu após as obras do PAC 2 "Minha casa, Minha Vida", que após o serviço de terraplenagem ocasionaram o estreitamento do canal.

Figura 4 - Ponto crítico no canal Paracuri

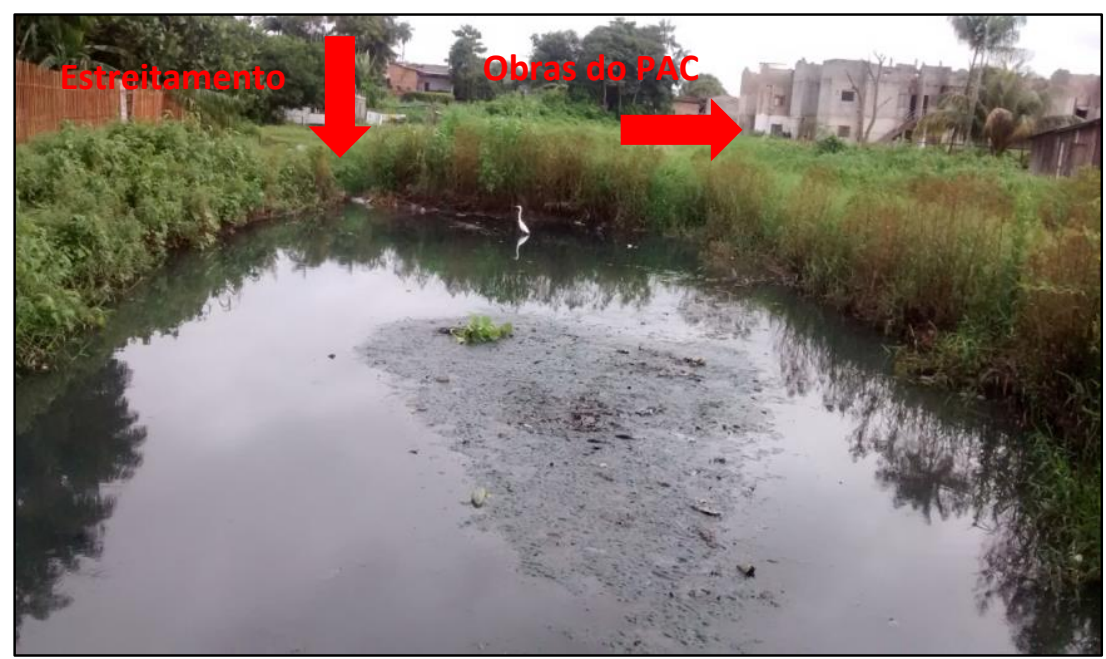




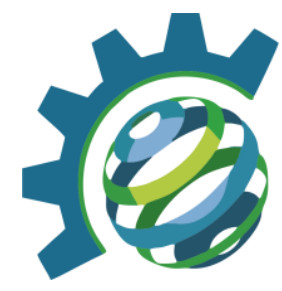

Esses fatos têm contribuído para um ambiente degradado (que nas condições atuais da Bacia do Paracuri tendem a piorar), resultante de um processo que infelizmente não está sendo contido, mas ampliado à proporção que o limite urbano aumenta (VINAGRE et al, 2015).

\section{CONCLUSÕES/RECOMENDAÇÕES}

Na cidade de Belém, sobretudo na bacia hidrográfica do Paracuri, o sistema de drenagem urbana (micro e macro), encontra-se em sua grande maioria, em estado de degradação, não desempenhando com eficiência suas funções e causando constantes transtornos a população, sobretudo no período de chuvas intensas.

Dessa forma, mesmo que seja realizada anualmente a limpeza dos canais e das sarjetas, por parte da Prefeitura Municipal de Belém, medida considerada de cunho paliativo, são necessárias ações mais efetivas, que visem solucionar os constantes alagamentos das periferias da bacia hidrográfica do Paracuri.

Recomenda-se a implantação de um sistema de gerenciamento adequado na região em que ocorra a disposição adequada dos resíduos sólidos, de forma que estes sejam dispostos somente nos pontos de coleta e dentro do período de recolhimento. Com isso, evitam-se pontos de acumulação de resíduos, a fim de resguardar os dispositivos de drenagem, que ficam obstruídos, sobretudo no período de chuvas intensas e podem funcionar de forma adequada.

Além disso, a questão do uso do solo deve ser analisada com o intuito de previnir a sua impermeabilização desenfreada, preservando-se áreas naturais que viabilizem a infiltração das águas pluviais. O uso de novas tecnologias de pavimentação permeável é interessante para diminuir o escoamento superficial, somado a construção de calçadas em blocos com espaçamentos suficientes para que ocorra a infiltração.

Quanto ao esgoto, verificou-se a necessidade de implantação imediata da rede coletora e, consequentemente, da estação de tratamento, com a finalidade de eliminar-se a descarga deste esgoto nas redes de drenagem. Deve haver um sistema separador absoluto aliado à eficiência dos dispositivos de drenagem, para então criar um ambiente salubre à população.

Outro ponto a ser trabalho, é o que diz respeito às habitações construídas nas áreas de várzea e que sofrem com constantes alagamentos nos períodos de chuvas intensas. Assim, devem ser aplicadas políticas habitacionais que garantam o exercício do plano diretor urbano, evitando que a população resida em lugares de risco. Também é imprescindível aliar a aplicação dessas técnicas de engenharia e urbanismo com ações de educação ambiental nas comunidades, a fim de despertar o senso de pertencimento da população ao meio ambiente em que vivem, tornando-os atores de conversão desse meio.

Portanto, o poder público deve evitar esperar apenas o período de chuvas na capital paraense para agir em relação aos dispositivos da micro e macrodrenagem, visto que é fundamental que se tenha periodicidade dos serviços de manutenção dos canais e planejamento adequado da drenagem urbana, que proponham medidas efetivas em longo prazo. 

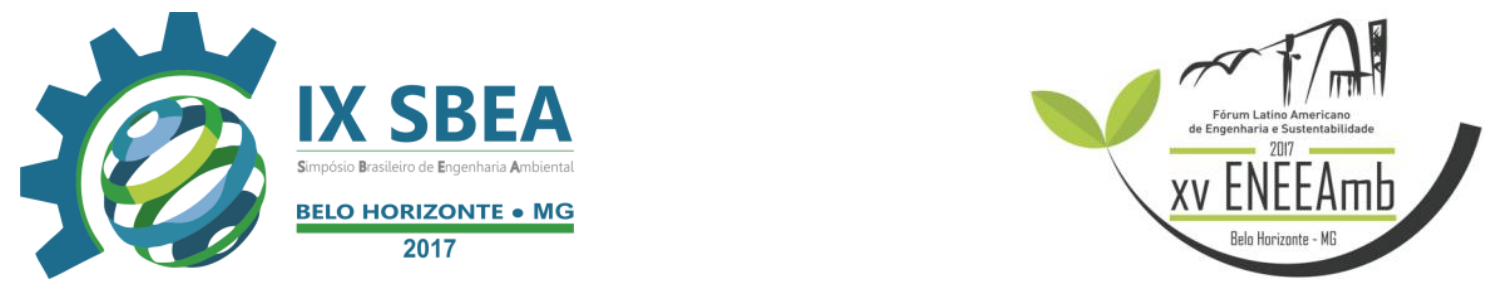

\section{REFERÊNCIAS BIBLIOGRÁFICAS}

ALCÂNTARA, R. S. et al. Vulnerabilidade socioambiental do bairro do Paracurci, IcoaraciPará. In: CONGRESSO BRASILEIRO DE GEÓGRAFOS, 7., Vitória: Anais do VII Congresso Brasileiro de Geografia. São Paulo: AGB, 2014.

AZEVEDO NETTO, J. M. A. Manual de Hidráulica. São Paulo: Blucher, 1998. 669 p.

BANDEIRA, I. C. N.; ALMEIDA, F. M.; DIAS, E. R. F.; MATTA, M. A. S.; FIGUEREDO, A. B.; MENDES, J. M. C. Aspectos de Vulnerabilidade Natural dos Sistemas Aquíferos da Bacia do Paracuri, Belém/PA. In: CONGRESSO BRASILEIRO DE ÁGUAS SUBTERRÂNEAS, 13, Cuiabá. Anais do XIII Congresso Brasileiro de Águas Subterrâneas, São Paulo: ABAS, 2004. p. 01- 16.

FRAGOSO, G. A.; SilvA, F. P.; SIlvA, J. C. C.; AlVES, A. F.; CARVAlHO, B. G. P. Diagnóstico do Sistema de Drenagem Urbana da Cidade de Belém, Pará: uma análise dos principais bairros da cidade. In: ENCONTRO NACIONAL DE ESTUDANTES DE ENGENHARIA AMBIENTAL, 24., Brasília. Anais do XIV Encontro Nacional de Engenharia Ambiental [= Blucher Engineering Proceedings v. 3 n.2]. São Paulo: Blucher, 2016. p. 1263-1269.

GOMES, E. S. A Urbanização e os Assentamentos Precários na Bacia do Paracuri Belém-PA. Belém, 119 p., 2014. Dissertação (Mestrado) - Universidade Federal do Pará.

INSTITUTO BRASILEIRO DE GEOGRAFIA E ESTATÍSTICA- IBGE. SIDRA. [Planilhas eletrônicas]. Disponível em: <https://sidra.ibge.gov.br/home/pnadcm>. Acesso em: 30 mai. 2017.

MATTA, M. A. S.; ALMEIDA, F. M.; DIAS, E. R. F.; BANDEIRA, I. C. N.; FIGUEREDO, A. B. Geometria dos Sistemas Aquíferos da Bacia Hidrográfica do Paracuri - Belém/PA, como base para uma proposta de abastecimento de água subterrânea. In: CONGRESSO BRASILEIRO DE ÁGUAS SUBTERRÂNEAS, 13, Cuiabá. Anais do XIII Congresso Brasileiro de Águas Subterrâneas, São Paulo: ABAS, 2004. p. 01- 17.

PAIVA, K. F. G. M. Análise Geoambiental da Bacia do Igarapé Paracuri, distrito de Icoaraci, Belém-PA: subsídios para um desenvolvimento urbano sustentável. Revista Cientifica da UFPA, Belém, v. 2, n. 3, 2002.

RODRIGUES, R. M.; TAVARES, A. N. M.; MIRANDA, T. B. Urbanizar as "baixadas": experiências de projetos de urbanização de assentamentos precários em áreas de preservação permanente em Belém (PA). In: ENCONTRO DA ASSOCIAÇÃO NACIONAL DE PESQUISA E PÓS-GRADUAÇÃO EM ARQUITETURA E URBANISMO, 4., Porto Alegre. Anais do IV Enaparq, Porto Alegre, 25-29 jul. 2016 [recurso eletrônico], Porto Alegre: PROPAR/UFRGS, 2016. 

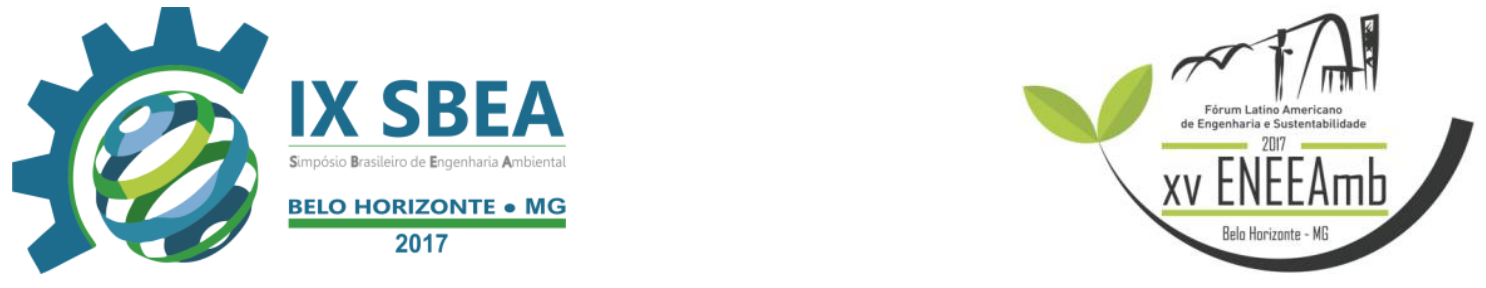

SANTOS, M. A. V. Manejo de águas pluviais e a sustentabilidade da drenagem urbana: estudo sobre o serviço de manutenção e conservação da drenagem de Salvador. Salvador, 152 p., 2009. Dissertação (Mestrado) - Universidade Federal da Bahia.

VINAGRE, M. V. A.; LIMA, A. C. M.; LIMA Junior, D. L. Estudo do comportamento hidráulico da Bacia do Paracuri em Belém (PA) utilizando o programa Storm Water Managemente Model. Revista Engenharia Sanitária e Ambiental, Rio de Janeiro, v. 20, n. 3, p. 361-368, 2015.

TREVISOL, J. P.; BACK, A. J. Avaliação dos Impactos da Urbanização na Drenagem Superficial no Centro de Forquilhinha, SC. Criciúma, 20 p., 2011. Monografia Universidade do Extremo Sul Catarinense. 